such evidence has been given before a committee or an agreed arbitrator, each medical witness shall sign the statement of his evidence and may add any necessary explanation or correction," and that statement seems to be used generally for a report or statement made in writing. The question is one of interest and will, no doubt, be raised and decided anthoritatively before very long.-ED. L.

\section{SCHOLARSHIPS FOR RESEARCH ON THE EFFECTS OF ALCOHOL.}

To the Elitors of THE LANCET.

SIRS,-I note with surprise in your leading article on the giving of scholarships for research on the effects of alcohol by the National Temperance League that you heartily commend the movement. What value such a research, conducted under the auspices of a strongly biased syndicate and superintended by those who are well known to be prejudiced, can possibly have I for one entirely fail to see. The teetotal attitude towards science in the past has been very much like that of the Caledonian Sabbatarian who, when he was reminded that Christ regarded the Sabbath from a less narrow point of view than he did, replied that he knew it and did not think any the better of Him for so doing.

When science has appeared to support total abstinence well and good, but if not then so much the worse for science. A hundred fallacies are apt to creep into such an attempt as this to reduce to the limits of an exact science what is essentially an inexact one. It has been stated that frog and pigeon physiology has been the bane of clinical medicine, so likewise are these psendo-scientific investigations instituted not really with a view of arriving at an impartial judgmen but to bolste $\mathbf{r}$ up a particular fad, and "At the outset this over whelming difficulty presents itself that that which is harmful to one person may be indifferent in its effects upon another or even beneficial to him."

You lay stress upon the fact that only men who have the confidence of the profession are to be chosen, but the names published are those of well-known teetotalers. As well might one expect to arrive at an impartial judgment regarding, let us say, the question of vivisection by studying the results of a research carried out by the antivivisectionists. These investigators are to test the effects of alcohol upon a man's capacity for work, but the capacity for work (unless the man's whole life's work be reviewed) is not a determining factor in the case for over-activity and an apparently increased power for work may be as much due to an abnormal state as the opposite condition. Reaction-time experiments upon which so much stress has been laid give us no real information as to the ultimate benefit to be derived from the use of alcohol which in certain quantities temporarily slows or hinders the output of energy, but whether this is good or bad for the individual must be determined by experience alone. I can remember a food fadaist who tried to live almost entirely on nuts, boasting that he could walk 40 miles without undue fatigue, but he died young after an illness due to the effects of this régime and no doubt his extreme energy was due to an altogether abnormal physiological condition.

In a recent work under similar auspices, entitled "Alcohol and the Human Body," it is never made clear to the reader whether the use or the abuse of alcohol is under discussion it is to be hoped that in this investigation they will at least not confound the man "saturated with alcohol" with the temperate user of the same.

I am, Sirs, yours faithfully,

Old Burlington-street, W., Oct. 13th, 1907.

A. W. FULLER.

\section{MALARIA IN ANCIENT GREECE AND ROME. \\ To the Editors of THE LANCET.}

SIRS,-The little book which has just appeared on the above subject is necessarily limited in scope, as its true object is to show how malaria affects character and sometimes even influences the destiny of nations. But there are a few other points which are, I think, worthy of attention at the bands of medical men. A modern physician, in diagnosing a case of malaria, relies upon his thermometer, his microscope, and the action of quinine. The ancient doctor used perforce his eyes and his fingers, which accordingly became so sensitive that symptoms were noticed which seem to have escaped modern observers. A study of these symptoms might throw light upon some problems of tropical and sub-tropical disease, for a physician like Galen had the accumulated experience of centuries to help him in forming his conclusions.

A large portion, perhaps some hundreds of pages, of the ancient medical writers describe fevers having symptoms suggestive now of typhoid, now of malaria. Of these fevers some may be Malta fever, many are doubtless remittent malaria, but most appear to be cases of typhoid in patients previously infected with the malaria parasite. Instances of this must have been extremely common in highly malarious districts like parts of ancient Greece and Italy. Further study of the Hippocratic treatises, which of course imply much experience previous to Hippocrates, convinces me that the Greeks of the East were familiar with malaria long before it became endemic in Attica. Will anyone try to discover whether malaria influenced the history of the Assyrians and the Persians?

Cambridge, Oct. 5th, 1907. I am, Sirs, yours faithfully,

\section{MEDICAL EXAMINERS TO INSURANCE COMPANIES. \\ To the Editors of THE LANCET.}

SIRs-Complaints still continue to reach us from medical men who have been induced to take out policies in insurance companies by promises of appointments as district medical examiners to the companies. The fees they are led to expect do not accrue. Will you, therefore, kindly allow me through your columns to warn medical practitioners against all insurance companies which offer the position of district medical examiner in return for a policy? I am, Sirs, yours faithfully,

Hugh Woods

General Secretary, London and Counties Medical Protection Society, Limited.

Craven-street, Strand, W.C.

\section{MOTOR DRIVER'S PALSY.}

To the Editors of THE LANCET.

SIRs,-I was recently consulted by a patient about what appears to be a new form of occupation or craft palsy due to driving a motor car. The patient's complaint was that on waking in the morning his left hand was firmly closed. He could extend the first two fingers with some difficulty but the last two had to be rubbed and forcibly extended before the spasm was overcome. There seems to be some discomfort at all times not amounting to pain. The only explanation which is forthcoming is that he has driven his car himself for the past year or two, and on driving with him noticed that he maintained a constant grip with his left hand, all the levers being operated by the right. I have not come across this condition before, but perhaps some of your readers may have seen it and may be able from experience to say whether there is any cure for it short of giving up driving. It is conceivable that, just as occurs in writer's palsy, the voluntary control of the muscles might be abrogated without warning, the consequence of which might be a serious accident.-I am, Sirs, yours faithfully,

Putney, Oct. 12th, $1907 . \quad$ DONALD F. SHEARER.

\section{A DISCLAIMER.}

To the Editors of THE LANCET.

SIRs, - I wrote to you yesterday that through no fault of mine a sensational account of a lecture by me has appeared in the general press. I see to-day extracts from it put together as if there had been an interview. I cannot describe how profoundly sorry I am that this discreditable sensation has occurred and wish to tender my humblest apologies through your medium to all members of my proftssion. I may hold singular individual views but I have no desire to ventilate medical matters through the lay press. I am, Sirs, yours respectfully,

Welbect-street, W., Oct. 10th, 1907 . BERNARD HoLLANDER. 